\title{
Inducible laryngeal obstruction: an official joint European Respiratory Society and European Laryngological Society statement
}

\begin{abstract}
Thomas Halvorsen (101, Emil Schwarz Walsted (10) ${ }^{2,3}$, Caterina Bucca ${ }^{4}$, Andrew Bush ${ }^{5}$, Giovanna Cantarella ${ }^{6}$, Gerhard Friedrich ${ }^{7}$, Felix J.F. Herth ${ }^{8}$, James H. Hull ${ }^{2}$, Harald Jung ${ }^{9}$, Robert Maat ${ }^{10}$, Leif Nordang ${ }^{11}$, Marc Remacle ${ }^{12}$, Niels Rasmussen ${ }^{13}$, Janet A. Wilson (1) ${ }^{14}$ and John-Helge Heimdal ${ }^{15}$

Affiliations: 'Dept of Pediatrics, Haukeland University Hospital and Department of Clinical Science, University of Bergen, Bergen, Norway. ${ }^{2}$ Dept of Respiratory Medicine, Royal Brompton Hospital, London, UK. ${ }^{3}$ Respiratory Research Unit, Bispebjerg University Hospital, Copenhagen, Denmark. ${ }^{4}$ Dept of Medical Sciences, University of Turin and Respiratory Unit, Città della Salute e della Scienza, Turin, Italy. ${ }^{5}$ Paediatric Respiratory Medicine, Imperial College and Royal Brompton Hospital, London, UK. 'OOtolaryngology Dept, Fondazione IRCCS Ca' Granda Ospedale Maggiore Policlinico, Milan, Italy. ${ }^{7}$ Dept of Phoniatrics, Speech and Swallowing, ENT Hospital Graz, Medical University of Graz, Graz, Austria. ${ }^{8}$ Dept of Pneumology and Critical Care Medicine, Translational Lung Research Center Heidelberg. Thoraxklinik, University of Heidelberg. Heidelberg, Germany. ${ }^{9}$ Hochgebirgsklinik Davos, Davos, Swiss Confederation. ${ }^{10}$ Dept of Otorhinolaryngology, Röpcke-Zweers Hospital, Hardenberg. The Netherlands. ${ }^{11}$ Dept of Surgical Sciences, Otorhinolaryngology and Head and Neck Surgery, Uppsala University, Uppsala, Sweden. ${ }^{12}$ Dept of ORL, Head and Neck Surgery, Louvain University Hospital of Mont-Godinne, Yvoir, Belgium. ${ }^{13}$ Dept of Otolaryngology, Head and Neck Surgery, Rigshospitalet, Copenhagen and University of Copenhagen, Copenhagen, Denmark. ${ }^{14}$ Dept of Otolaryngology, Head and Neck Surgery, Newcastle University and Freeman Hospital, Newcastle upon Tyne, UK. 15Dept of Surgery, Haukeland University Hospital and Dept of Clinical Science, University of Bergen, Bergen, Norway.
\end{abstract}

Correspondence: Thomas Halvorsen, Dept of Pediatrics, Haukeland University Hospital, 5021 Bergen, Norway. E-mail: thomas.halvorsendahelse-bergen.no

@ERSpublications

The larynx in respiratory medicine: an updated official statement from the ERS and ELS http://ow.ly/2WQ130dqLPp

Cite this article as: Halvorsen T, Walsted ES, Bucca C, et al. Inducible laryngeal obstruction: an official joint European Respiratory Society and European Laryngological Society statement. Eur Respir J 2017; 50: 1602221 [https://doi.org/10.1183/13993003.02221-2016].

ABSTRACT Inducible laryngeal obstruction (ILO) describes an inappropriate, transient, reversible narrowing of the larynx in response to external triggers. ILO is an important cause of a variety of respiratory symptoms and can mimic asthma. Current understanding of ILO has been hampered by imprecise nomenclature and variable approaches to assessment and management. A task force of the European Respiratory Society (ERS) and European Laryngological Society (ELS) was thus set up to address this, and to identify research priorities.

A literature search identified relevant articles published until June 2016, using all identifiable terms for ILO, although including only articles using laryngoscopy. In total, 172 out of 252 articles met the inclusion criteria, summarised in sections on diagnostic approach, aetiology, comorbidities, epidemiology and treatment. The consensus taxonomy published by ERS, ELS and the American College of Chest Physicians (ACCP) in 2015 is used throughout this statement.

We highlight the high prevalence of ILO and the clinical impact for those affected. Despite recent advances, most aspects of this condition unfortunately remain incompletely understood, precluding firm guidance. Specifically, validated diagnostic and treatment algorithms are yet to be established, and no randomised control studies were identified in this search; hence we also make recommendations for future research. 


\section{Introduction}

A seminal report was published in the New England Journal of Medicine in 1983, describing the characteristics of five patients who presented with unexplained dyspnoea and wheeze [1]. Although they mimicked asthma, these clinical features arose from inappropriate or "paradoxical" laryngeal closure. This description of vocal cord dysfunction (VCD) highlighted the importance of functional laryngeal obstruction (i.e. without apparent structural or neurological cause) as a distinct clinical entity. The authors proposed that the disorder was likely to "be more common than originally thought and may be part of a spectrum of breathing disorders related to abnormalities of the larynx".

Since that time, our understanding of disorders associated with paroxysmal laryngeal closure has evolved, and there are currently a large number of published reports describing the epidemiology, aetiology, clinical characteristics and treatment options. Moreover, technical advances have enabled dynamic endoscopic assessment of the upper airway. As a result, there is a growing understanding of the variety of phenotypes that might lead to laryngeal closure [2] and a growing awareness of the high prevalence of laryngeal closure causing exertional breathing problems in otherwise healthy young individuals [3].

In response to this evolving evidence base, a task force for inducible laryngeal obstruction (ILO) was established in 2010, including paediatricians, pulmonologists and otorhinolaryngologists with specific expertise in this field. The task force had two key aims: 1) to provide and establish an internationally accepted consensus nomenclature to describe paroxysmal and episodic laryngeal closure and 2) to evaluate the literature in the field; in order to identify important deficits in our current clinical knowledge base and thus direct future research priorities.

The first aim was achieved with collaboration between the European Respiratory Society (ERS), the European Laryngological Society (ELS) and the American College of Chest Physicians (ACCP) at the ERS/ELS/ACCP 2013 International Consensus Conference. The term ILO was accepted and defined as inducible (i.e. by an external stimulus) laryngeal obstruction causing breathing problems; this term will be used throughout this article [4].

This article, authored by the current ERS and ELS task force panel members, describes work addressing the second aim: detailing the findings of a systematic literature search, to present a state-of-the-art review on ILO. A key aim of this task force document is to use this appraisal process to make recommendations for future research, with the ultimate aim of facilitating and directing successful ongoing expansion of scientific knowledge in the field.

\section{Methodology}

Relevant articles published before July 2016 were identified by systematic searches in the Medline database (accessed through PubMed) and the Cochrane Database of Systematic Reviews. All possible terms for ILO known to the task force members were used in searches (a full list of search terms is presented in the online supplementary material). Additionally, reference lists from all articles where the subject of the publication fulfilled the ILO definition were further examined, and previously unidentified relevant publications were included. Only papers in English were selected, allowing all task force members to evaluate them. All original studies, cases, letters or other articles presenting new data with content matching the applied definition of ILO were included for further evaluation. The methodology for article selection is illustrated in figure 1 .

We excluded reports in which the diagnosis of ILO was based solely upon symptoms or clinical features of laryngeal obstruction. Thus, the current review only includes reports describing objectively verified laryngeal obstruction, i.e. by fibre-optic laryngoscopy or imaging.

We classified the articles into expert opinion, case reports/case series, cohort studies, case-control studies or randomised clinical trials.

Electronic copies of all identified articles were made available to all members of the task force group. The entire manuscript was drafted and amended until supported unanimously by all task force members.

This article has supplementary material available from erj.ersjournals.com

Received: Nov 102016 | Accepted after revision: May 202017

This statement was endorsed by the European Respiratory Society and the European Laryngological Society in July 2017.

Conflict of interest: Disclosures can be found alongside this article at erj.ersjournals.com 
FIGURE 1 Search methodology. ILO: inducible laryngeal obstruction.

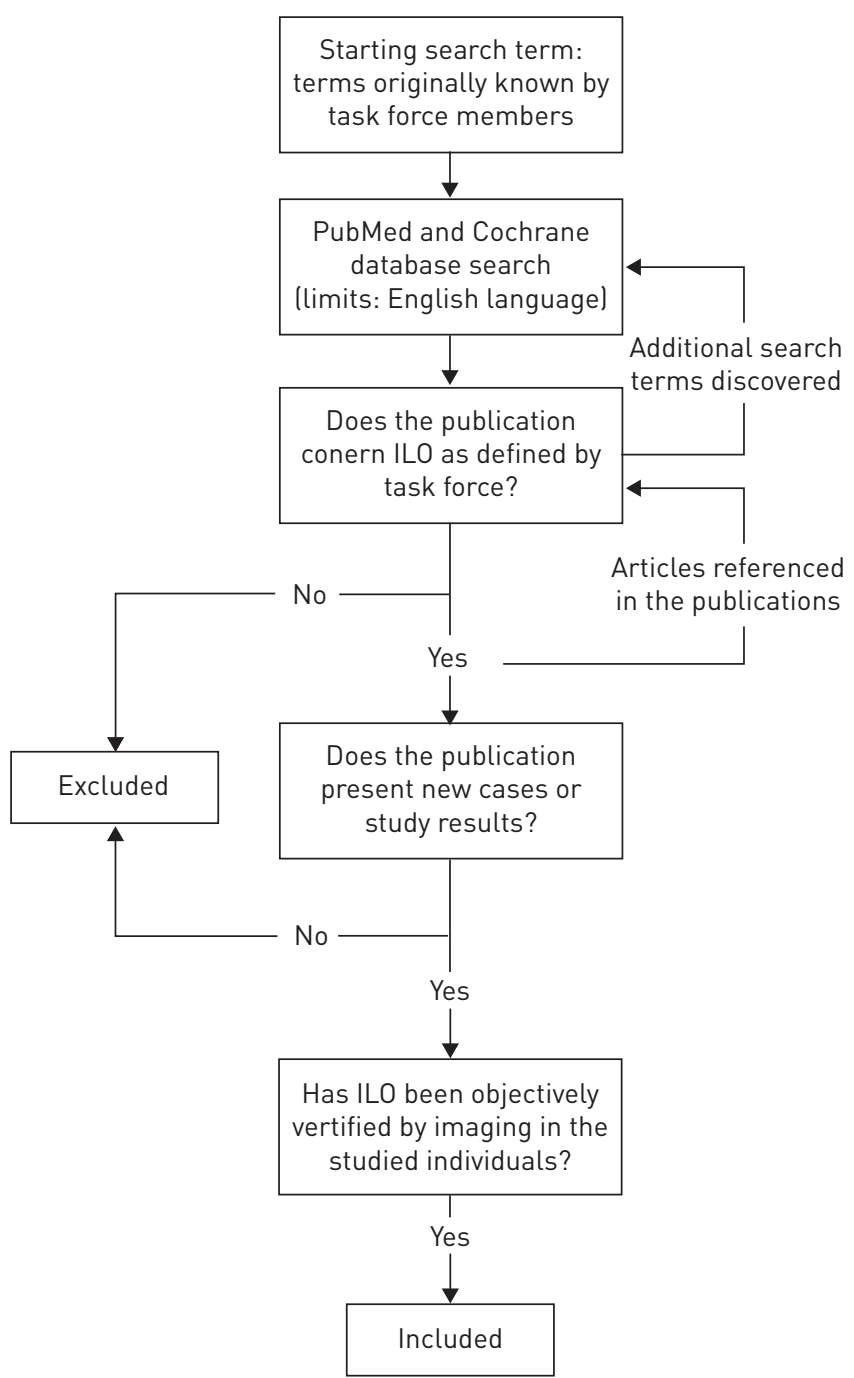

The primary search identified 252 articles for further examination. 172 articles matched the definition of ILO. Summary statistics of all matching articles can be found in table 1 . The majority were classified as case reports or case series $(n=136)$, cohort studies $(n=25)$ or case-control studies $(n=11)$. No randomised controlled trials or expert opinion studies were identified.

\section{Diagnostic approach \\ Clinical features}

A secure diagnosis of ILO is dependent on the presence of compatible clinical features, precipitated by exposure to an inducer or trigger and with concurrent objective verification of laryngeal obstruction, ideally by direct laryngoscopic examination [4].

Typical clinical features include wheeze, dyspnoea and cough, and these symptoms are highly variable and evanescent. In most cases, individuals with ILO will exhibit inspiratory breathing difficulties, although a pure expiratory form of ILO has been described [5].

When exercise is the inducer, the timing of symptom onset is informative. Symptoms of exercise-induced laryngeal obstruction (EILO) are typically maximal during strenuous exercise, in contrast to exercise-induced bronchoconstriction, in which symptoms typically can peak up to 20 min after exercise cessation. Dyspnoea caused by EILO can be accompanied by coarse or high-pitched inspiratory breath sounds, sometimes progressing to clear-cut stridor, and may be associated with severe respiratory distress, hyperpnoea and/or panic reactions, evolving in parallel with increasing ventilatory requirements throughout the exercise session. The term exercise-induced inspiratory symptoms has been introduced [2]; however, patients suffering from EILO are sometimes unable to attribute respiratory symptoms to a 
TABLE 1 Summary of included articles

\begin{tabular}{lcccc} 
& Studies & \multicolumn{3}{c}{ Patients } \\
\cline { 3 - 5 } & & Mean & Median & Total \\
\hline Case report or case series & 136 & 6 & 1 & 868 \\
Case-control & 11 & 75 & 97 & 826 \\
Cross-sectional & 25 & 59 & 60 & 1480 \\
Total & 172 & 18 & 1 & 3174 \\
\hline
\end{tabular}

Data are presented as $\mathrm{n}$.

specific phase of the breathing cycle, particularly when interviewed at a first consultation. Several studies indicate that self-reported symptoms are poor predictors of EILO $[3,6,7]$.

There are several symptom questionnaires that attempt to detect ILO [8-10]. These focus on the glottic component of ILO, with the exception of the dyspnoea index [9], and have yet to be comprehensively validated in a multicentre context. However, questionnaires show promise as diagnostic screening tools, while providing a structured description of symptoms.

\section{Laryngoscopic technique}

We have described previously how to perform a laryngoscopic examination and standards with regard to the key findings that should be reported in all cases [4]. Specifically, the change in laryngeal features from baseline to the point of maximal obstruction should be described. Furthermore, whether the obstruction to airflow is at a glottic or supraglottic level should be detailed [3, 6, 11-13]. In cases of combined supraglottic and glottic involvement, the two levels of obstruction may not be co-temporal throughout the attack. For multilevel obstruction, the sequence of events should be described if possible. It is helpful to record the laryngeal movement continuously for later analysis.

The degree of laryngeal obstruction can vary from mild to severe [12], with near-complete closure in some cases [1]. There is currently no gold-standard validated scoring system that differentiates normal from abnormal responses. Proposed methods for image quantification of the degree of obstruction have included measurement of laryngeal anterior-posterior (A-P) diameter [14-16] and measurement of anterior glottic angle [15]. Continuous recordings have used subjective reviewer grading estimates of obstruction [12] and computerised calculations relative to measured change in the glottic or supraglottic aperture [17].

Some authors have hypothesised that introducing a laryngoscope into the nasopharyngeal space and/or applying local anaesthetics to the nasal cavity may affect laryngeal reflexes and thus confound the results. Research is needed to address this issue, but there is currently no published evidence to support this notion.

\section{Inducers of laryngeal obstruction}

The most common inducers of laryngeal obstruction are exercise, irritants and emotional stress. An inducer in this context is defined by its ability to trigger sufficient narrowing of the laryngeal space to cause breathing difficulties and a laryngoscopic image compatible with laryngeal obstruction to airflow. The task force acknowledges that to a large extent, the latter is subjective. Therefore, while awaiting objective assessment of this feature (e.g. accurate measurements, validated scoring systems or pressure change measurements) the method by which this assessment was performed should be detailed.

\section{Exercise}

Where exercise is an inducer, laboratory provocation studies attempt to simulate the real-life (i.e. in the field) scenario, but most commonly employ an indoor treadmill [11, 17, 18], stationary bicycle [19] or, very occasionally, other exercise modalities [20].

Exercise protocols vary, but all aim to exercise subjects until symptoms are elicited and/or peak exercise capacity has been achieved. EILO typically occurs at high levels of ventilation [13], which entails that a maximal exercise test protocol must be employed. These simulation methods have been applied in large studies of symptomatic individuals and in symptom-negative controls [2, 3, 6, 21], but their between-test reliability and validity remain to be established. Crucial in this context is the ability of the test set-up to facilitate sustained maximal efforts (beyond the aerobic threshold) for as long as necessary to induce 

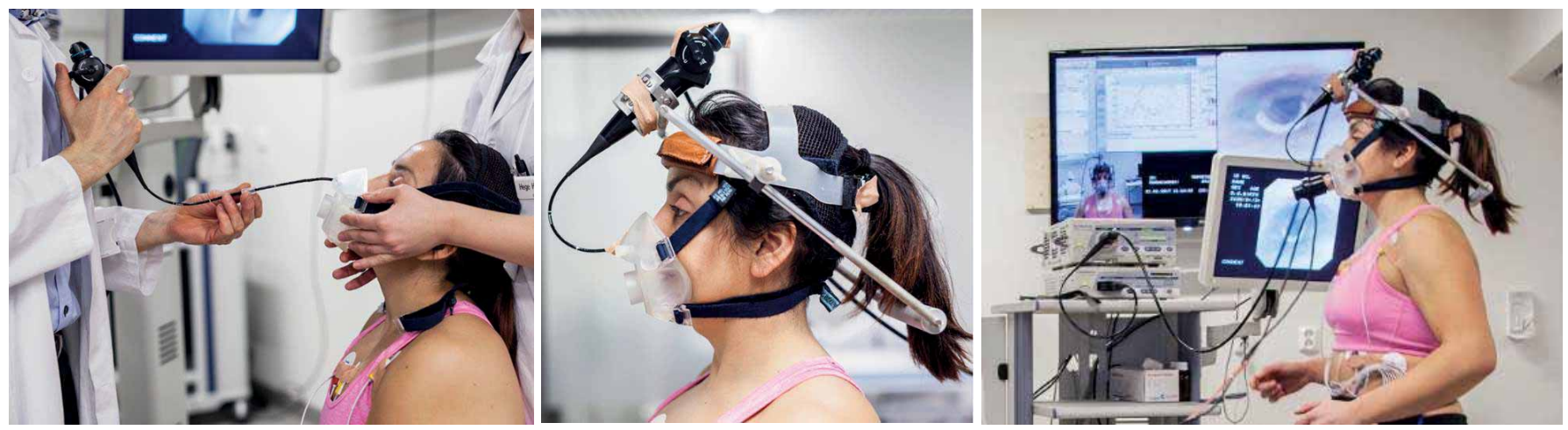

FIGURE 2 Continuous laryngoscopy during exercise. The laryngoscope is secured to a headset via a facemask. The screen shows real-time images of the patient, her larynx and cardiopulmonary exercise data while running.

symptoms. This might be more easily achieved if using free running or other 'in the field' techniques, as has been addressed in studies of exercise induced asthma [22]; however, this scenario has not been studied in relation to EILO.

The continuous laryngoscopy during exercise (CLE) test uses a flexible nasolaryngoscope fixed to a head apparatus, allowing real-time visualisation of the larynx throughout the study (figure 2) [11]. The CLE test has now been used in multiple research studies and provides recorded images detailing the temporal change of laryngeal obstruction, as it occurs during exercise [13]. The CLE test has helped establish the fact that EILO commonly arises from supraglottic (i.e. aryepiglottic fold) obstruction; however, in some cases it may be a pure glottic (i.e. vocal cord) phenomenon, or both can occur [2]. The relationship between laboratory EILO and EILO "in the field" is yet to be studied, and anecdotally, many athletes report heightened symptoms in the competitive environment (e.g. potential anxiety and physicality of competitive sporting events).

\section{Irritants}

A retrospective review included the first description of "irritant"-associated vocal cord dysfunction [23]. A variety of breathing and other problems were temporally associated with a single occupational $(\mathrm{n}=10)$ or environmental $(\mathrm{n}=1)$ exposure, based upon history alone, with no environmental exposure analysis. Inclusion required the patient's perception of a "gas smoke, fume, vapour, mist or dust". In several cases "...the exact offending agent(s) could not be determined..." nor was a physical "irritant" or injury effect documented, yet there was a presumptive attribution to "irritant inhalational injury". A broad range of irritants have been described in case reports and case series, including odours [10, 24, 25], sleep [26], stress [10], cold air [10], gastrolaryngeal reflux [27], environmental and occupational exposures [28-30], wood dust [31] and chemicals [29,32, 33]. The causal mechanism of irritant ILO is unknown. It is unclear if irritant ILO is a direct response to the irritant stimulus itself, e.g. via mucosal inflammatory reactions, or related to altered reflex sensitivity, and to what extent psychological factors contribute; highlighting the lack of evidence in the field.

\section{Use of surrogate inducers}

Substitute (surrogate) methods for the inducer have been used to precipitate ILO. Specifically, the use of methacholine [7, 34], mannitol [7] and histamine [14, 35, 36] as laryngeal provocation agents has been studied, using standard bronchoprovocation test methodologies, but with a focus on the inspiratory component of the flow-volume loop on spirometric measurements.

The relationship between bronchoprovocation testing and ILO is complex and incompletely understood. Indeed, patients with laryngoscopic evidence of ILO may have ILO during methacholine challenge, as well as with saline placebo [37]. Many authors have concluded that methacholine challenge is of little help in differentiating EILO from asthma, and indeed, the two conditions may coexist [37-40]. In addition, it remains unclear whether substitute inducers and self-induction are comparable to the laryngeal response during a typical "symptomatic" episode.

Eucapnic voluntary hyperpnoea has been used with direct laryngoscopic visualisation [41], and can induce glottic as well as supraglottic obstruction. However, the sensitivity and specificity of these findings remain unclear, and in one study the authors commented that poor visualisation of the larynx limited the utility of this technique [41]. 
Use of surrogate means to detect laryngeal obstruction

Diagnostic methods other than laryngoscopy have been evaluated in the diagnosis of ILO; most often full flow-volume measurement with spirometry. Patients with ILO [1] typically have a normal flow-volume loop while asymptomatic; however, during a spontaneous episode a variable extrathoracic obstruction pattern can be present, i.e. with attenuation in the inspiratory flow compared to expiratory flow $[1,5,39$, 40, 42-44]. There are several causes of a blunted or truncated inspiratory flow-volume curve, including inadequate instruction, suboptimal effort or inability to perform the procedure, as well as other diseases such as diaphragm weakness, fixed large airway obstruction and any cause of reduced lung compliance [37]. It is therefore not surprising that the diagnostic precision of spirometric assessment of ILO is poor $[39,43]$. One study evaluated the flow-volume loop before and after exercise, and found no correlation with laryngoscopy-documented ILO. The authors concluded that exercise-induced laryngeal obstruction cannot be diagnosed or excluded by physician-evaluated pre- and post-exercise flow-volume loops [45]. Similarly, assessment of intra-exercise tidal flow-volume relationships has not been systematically validated in a context of EILO diagnostics, presently precluding evidence-based use of these measures. Finally, flowvolume loops cannot differentiate supraglottic from glottic ILO, distinctions that have a bearing on choice of treatment. Thus, the use of flow-volume loops (resting and intra-exercise) as diagnostic tool in ILO needs to be further explored in future studies.

Forced oscillation techniques may be a diagnostic or screening tool for ILO [46-49]; however, the sensitivity and specificity of these methods are insufficiently described and more research is needed.

Computed tomography, with three-dimensional images of laryngeal obstructions, has been reported to identify ILO in a cohort of patients with difficult-to-treat asthma [50]. Limitations of this technique include the absence of documentation of a symptomatic spontaneous or provoked episode during testing, need for supine positioning and brief data acquisition window, due to concerns about radiation exposure.

\section{Epidemiology}

The reported epidemiology of ILO varies considerably, depending on the diagnostic criteria employed (table 2). Moreover, the literature is replete with case reports and small case series highlighting a number of questionable associations, for example a high prevalence of psychiatric comorbidity [1], some of which may be examples of Berkson's fallacy. Moreover, although clinical cohort studies of patients with ILO have now been published (table 2), any given cohort will be heavily influenced by referral bias and the perspectives of the authors, varying between psychiatric departments [51], paediatric departments [2], highly specialised otorhinolaryngology clinics [52], military institutions [43] and sports medicine settings $[6,40]$.

Key epidemiological data, such as prevalence, incidence, age and sex distribution of ILO are unknown in the general population. Newman et al. [5] described 95 adults ( $84 \%$ female) hospitalised with laryngeal symptoms, with an average age of 39 years. In an evaluation of 1025 patients with dyspnoea, prescreening identified 63 potential patients of whom $29(2.8 \%)$ were diagnosed with ILO [53]. When classified according to the original nomenclature of VCD in a 2010 review $(n=1161)$, there was an approximately 2:1 female predominance, $71 \%$ were adults and the remaining $29 \%$ were predominantly adolescents [54].

The prevalence of EILO in adolescents and young adults appears to be in the range of 5-7\% in northern Europe [3,21]. Some, but not all studies report a higher female prevalence, discrepancies possibly related to the age of the subjects at assessment in the various studies. Thus, in a study of 94 patients diagnosed using the CLE test, average age was $\sim 15$ years, and $68 \%$ were female [55], similar to other adolescent groups (table 2). Exercise appears to be a more common inducer of ILO in younger age groups; however, this might be a biased impression based on different exercise habits in the different phases of life.

Details on presumed "irritant" ILO are limited, as irritant exposure is a less frequently reported inducer than exercise. In 11 cases of irritant-associated VCD, $73 \%$ were female and of a similar age (45 years) to a nonirritant-exposed VCD control group $(n=33)$ with a $94 \%$ female predominance [23]. Evaluation of spirometry from workers at the World Trade Center disaster identified a cohort with possible irritant-induced VCD. From a sample of 172 individuals, $18.6 \%$ had variable extrathoracic obstruction and 10 (5.8\%) patients were diagnosed with VCD [30].

\section{Aetiology/pathophysiology}

The human larynx has a number of highly complex functions; it must close to protect the airway from life-threatening aspiration, but must open fully during exercise in order to optimise airflow and thus exercise performance. Finally, it performs fine movements during phonation. Given these sophisticated roles it seems unlikely that a single factor could explain the entire range of manifestations of ILO. 
TABLE 2 Key studies detailing the epidemiology of inducible laryngeal obstruction (ILO)

\begin{tabular}{|c|c|c|c|c|c|}
\hline $\begin{array}{l}\text { Authors } \\
\text { [reference] }\end{array}$ & Year & Population & Design & Findings & Comments \\
\hline $\begin{array}{l}\text { HIRA and SINGH } \\
\text { [46] }\end{array}$ & 2009 & $\begin{array}{l}\mathrm{n}=51 \\
\text { Patients referred to } \\
\text { tertiary centre for } \\
\text { treatment-refractory } \\
\text { asthma }\end{array}$ & Cross-sectional & $\begin{array}{l}24 \% \text { had VCD } \\
\text { Age } 32.9 \pm 12.4 \text { years } \\
58 \% \text { female } \\
\text { IOS-positive in } 58 \% \text { of cases and } \\
\quad 15 \% \text { of controls }\end{array}$ & $\begin{array}{l}\text { Only considers glottic ILO } \\
\text { diagnosed at rest }\end{array}$ \\
\hline $\begin{array}{l}\text { NieLSEN } \\
\text { et al. [6] }\end{array}$ & 2013 & $\begin{array}{l}\mathrm{n}=88 \\
\text { Athletes referred to CLE } \\
\text { in a tertiary asthma } \\
\text { clinic }\end{array}$ & Case series & $\begin{array}{l}35 \% \text { had EILO } \\
\text { Median (IQR) age } 18(11) \text { years } 77 \% \\
\text { female } \\
43 \% \text { had verified asthma }\end{array}$ & $\begin{array}{l}\text { Retrospective design } \\
\text { Highly selected population }\end{array}$ \\
\hline $\begin{array}{l}\text { HANKS } \\
\text { et al. [105] }\end{array}$ & 2012 & $\begin{array}{l}\mathrm{n}=148 \\
\text { Athletes referred to a } \\
\text { tertiary asthma clinic } \\
\text { for evaluation of } \\
\text { exertional dyspnoea }\end{array}$ & Cross-sectional & $\begin{array}{l}70 \% \text { of tested ( } n=82 \text { ) had VCD } \\
\text { Median age } 19 \text { years } \\
73 \% \text { female } \\
31 \% \text { of VCD-positive subjects had } \\
\text { verified ElB } \\
6 \% \text { had verified asthma }\end{array}$ & $\begin{array}{l}\text { Retrospective design } \\
\text { Diagnosis by } \\
\text { videolaryngostroboscopy }\end{array}$ \\
\hline $\begin{array}{l}\text { JohansSON } \\
\text { et al. [3] }\end{array}$ & 2015 & $\begin{array}{l}\mathrm{n}=125 \text { (n=2309 screened) } \\
\text { General population with } \\
\quad \text { exertional dyspnoea }\end{array}$ & Cross-sectional & $\begin{array}{l}11 \% \text { of cases and } 4 \% \text { of controls } \\
\text { had EILO } \\
\text { Mean (range) age } 14.2(13-15) \text { years } \\
\text { Estimated prevalence of EILO in } \\
\text { the general population: } 5.7 \% \\
\text { (equal for male and female) } 44 \% \\
\text { of EILO-positive subjects had } \\
\text { verified EIB }\end{array}$ & $\begin{array}{l}\text { Well-designed } \\
\text { Did not report details on } \\
\text { glottic/supraglottic } \\
\text { components }\end{array}$ \\
\hline
\end{tabular}




\section{TABLE 2 Continued}

\begin{tabular}{|c|c|c|c|c|c|}
\hline $\begin{array}{l}\text { Authors } \\
\text { [reference] }\end{array}$ & Year & Population & Design & Findings & Comments \\
\hline $\begin{array}{l}\text { HILLAND } \\
\text { et al. [58] }\end{array}$ & 2016 & $\begin{array}{l}\mathrm{n}=20 \text { (cases) } \\
\text { Patients with a history of } \\
\text { childhood } \\
\text { laryngomalacia } \\
\text { requiring hospital } \\
\text { admission }\end{array}$ & Case-control & $\begin{array}{l}70 \% \text { EILO-positive } \\
\text { Age } 12.7 \pm 2.7 \text { years } \\
35 \% \text { female } \\
70 \% \text { supraglottic } \\
45 \% \text { of EILO-positive subjects had } \\
\text { anomalies at rest }\end{array}$ & Highly selected population \\
\hline $\begin{array}{l}\text { WALSTED } \\
\text { et al. [7] }\end{array}$ & 2016 & $\begin{array}{l}\mathrm{n}=37 \\
\text { Patients with suspected } \\
\text { asthma and exertional } \\
\text { dyspnoea referred to a } \\
\text { tertiary asthma clinic }\end{array}$ & Cross-sectional & $\begin{array}{l}22 \% \text { EILO-positive } \\
\text { Median (IQR) age } 22.5 \text { (12) years } \\
100 \% \text { female } \\
88 \% \text { supraglottic } \\
14 \% \text { of EILO-positive had verified } \\
\text { asthma } \\
\text { Inspiratory flow in mannitol and } \\
\text { methacholine tests were poor } \\
\text { predictors of EILO }\end{array}$ & Selected population \\
\hline
\end{tabular}

Data are presented as mean \pm SD or median (range), unless otherwise stated. VCD: vocal cord dysfunction; IOS: impulse oscillometry; EILO: exercise-induced laryngeal obstruction; CLE: continuous laryngoscopy during exercise; IQR: interquartile range; PVFMD: paradoxical vocal fold motion disorder; EIB: exercise-induced bronchoconstriction.

\section{Mechanical insufficiency}

It is likely that mechanical factors, based upon pressure change across the laryngeal inlet, are relevant in ILO triggered by exercise. The Bernoulli principle states that increasing airflow through a tube creates increasing negative pressures within that tube [56]. For the laryngeal aperture, the flow rate at which this will occur is determined by the area and configuration of the laryngeal opening and external support from surrounding structures. Thus, EILO may be explained by laxity of muscles, ligaments or the laryngeal cartilages. Of possible interest in this context is a relationship between congenital laryngomalacia (CLM) and EILO as proposed by SMITH et al. [57] in 1995, and a link from CLM to adolescent EILO proposed in a small study by HiLLAND et al. [58] in 2016. Certainly, there are no studies to date that indicate that EILO in general can be explained simply by CLM; however, these two studies underline that laryngeal structure does seem to be relevant for EILO and that a history of CLM may be of relevance in some subgroups.

The posterior cricoarytenoid (PCA) muscle is the principal laryngeal abductor. Thus, a malfunctioning PCA muscle may lead to a smaller laryngeal aperture, possibly to a size below a critical level during high airflow states (i.e. exercise) [59].

The presentation of EILO is most frequently described in early adolescence and more often in females $[2,3$, $21,37]$. The aryepiglottic folds and the cuneiform tubercles make the supraglottic opening relatively narrower in adolescents than in adults $[60,61]$. There is no sex difference in the relative size of the prepubertal laryngeal aperture, while significant sex differences are described to occur throughout the pubertal growth spurt [61, 62]. These factors may all contribute to the age and sex distribution of the EILO epidemiology. However, changes with time and growth or differences as regards exercise habits, symptom awareness or other factors could also be involved and this needs to be explored in studies.

\section{Neural dysfunction}

Neural reflex control is important for adequate laryngeal function in relation to respiration, swallowing and protection against aspiration. The hypothesis behind reflex-associated VCD is that direct stimulation of sensory nerve endings in the respiratory tract may induce a protective reflex, triggering laryngeal closure [23]. Mechanical or chemical stimulation of the supraglottic mucosa or direct stimulation of the superior laryngeal nerve may activate the laryngeal adductor reflex to protect the airway from aspiration or asphyxiation [63].

As discussed in detail below, gastro-oesophageal reflux (GOR; both acidic and nonacidic) may sensitise the glottal closure reflex [34, 64]. However, paradoxically, evaluating laryngeal sensitivity with direct mechanical stimulation has indicated reduced laryngeal sensitivity in the presence of reflux [65]. This may explain anecdotal reports of proton-pump inhibitors improving reflux, but not VCD [52]. Furthermore, 
and again anecdotally, a cold climate reduces exercise tolerance in patients with EILO, and inspiratory stridor is more prevalent in outdoor (8.3\%) compared to indoor athletes (2.5\%) [40]. Collectively, these observations indicate that environmental factors might be involved in the aetiology of EILO; however, mechanisms remain unknown and should be addressed in future studies.

\section{Psychological contribution}

Several studies indicate the importance of considering a psychological contribution in ILO [51, 66, 67]. Specifically, in a sample of 171 cases with paradoxical vocal cord motion, only $7 \%$ did not have a psychiatric diagnosis [51]. Others have claimed that VCD represents the physical manifestation of underlying psychological problems [68]. These statements have been disputed, with the authors arguing that the tendency for panic observed in some patients is caused by the choking feeling of laryngeal collapse during heavy exercise, rather than being the cause of EILO [2]. These complex issues need to be addressed in properly designed studies.

\section{Comorbidities}

Several comorbidities may contribute to ILO, including asthma, GOR disease and nasal disease (e.g. sinusitis).

\section{Asthma}

ILO has long been recognised to mimic asthma [1], but is increasingly recognised to coexist with asthma. The contribution of each to a given episode of respiratory distress may be difficult to determine.

The use of standard effort-dependent lung function methods for diagnosis of comorbid asthma requires reliable, consistent and reproducible results. However, patients with ILO have been reported to have difficulty performing reproducible maximal flow-volume loops [29, 33]. If the vital capacity is reduced due to inducible laryngeal inspiratory obstruction, the forced expiratory volume in $1 \mathrm{~s}$ (FEV1) is also likely to be reduced, potentially leading to an erroneous diagnosis of asthma, although the FEV1/forced vital capacity ratio may be normal and suggestive of a restrictive, not an obstructive, pattern. The flow-volume loop in a symptomatic patient with confirmed inspiratory and expiratory ILO, and unequivocally excluded asthma, can still demonstrate a concave reduction in expiratory flow, mimicking asthma. Moreover, if only the percentage reduction in FEV1 data is reviewed in interpretation of bronchoprovocation studies, such as a methacholine challenge, a misdiagnosis of asthma can be made.

Bronchoconstriction may itself induce laryngeal obstruction, which presents a significant barrier to the robust scientific study of asthma as a comorbidity of ILO. Use of endoscopic photography in normal subjects [14] demonstrated true vocal fold adduction on inspiration and expiration with reduced glottic area during histamine-induced bronchoconstriction measured with spirometry. Thereafter, 34 patients with obstructive lung disease of varying severity on spirometry were examined using endoscopic photography and calculation of glottic area referenced to a separately established constant A-P glottis diameter [69]. Results showed that glottic area (due to adduction of the true vocal folds) decreased proportionally to the decrease in FEV1 on inspiration and expiration, and was more pronounced on expiration.

Future investigations should utilise objective diagnostic methodology to explore the possible associations between ILO and asthma, and to elaborate on these rather old studies. However, two important practical points can be extracted from the available literature: every effort should be made to diagnose asthma objectively [70], and secondly; in known asthmatics, it should not be assumed that all episodes of respiratory distress are due to asthma.

\section{Reflux}

Objective studies using manometry or impedance in patients with documented ILO have not been conducted to confirm that GOR episodes occur in a temporal relationship to symptomatic ILO episodes [71]. Patients with documented GOR and cough had significantly reduced laryngopharyngeal sensitivity, defined as the lowest air pressure required to induce the laryngeal adductor reflex, a transient episode of true vocal cord adduction. In short, the laryngeal adductor reflex threshold was higher in the GOR group. Laryngopharyngeal sensitivity was then compared before and after laryngopharyngeal infusions of normal saline and $0.1 \mathrm{~N}$ hydrogen chloride on separate days. In normal subjects the laryngopharyngeal sensitivity threshold for the laryngeal adductor reflex was significantly raised with acid, but not saline infusion, suggesting that small amounts of acid infusion into the laryngopharynx significantly impaired sensory integrity. A follow-up study [72] confirmed that the laryngopharyngeal sensitivity threshold for the laryngeal adductor reflex was elevated in GOR. Nonetheless, a smaller volume of infusion directly into the laryngopharynx was required to trigger the laryngeal adductor reflex in patients with GOR than in normal controls. 
Nasal disease

Sinus computed tomography in patients with laryngoscopy-confirmed ILO was compared to patients presenting to the emergency room with acute asthma, patients with nonacute asthma and nonasthmatic controls [73]. There was extensive sinusitis in 23 of 74 acute asthmatics, five of 29 nonacute asthmatics, two of 59 controls and none of 13 ILO patients. The authors concluded that patients with ILO could be distinguished from asthma by sinus computed tomography, but the evidence is inconclusive, and in any event, the two frequently coexist.

\section{Treatment}

\section{General approach}

There are currently no published randomised controlled treatment trials. Even anecdotal reports frequently do not adequately confirm the diagnostic work-up and the outcome measure(s) that were applied, or characterise the type or severity of ILO. Multiple and often vaguely described management steps and a multitude of anecdotal reports complicate an overall interpretation. There is thus an urgent need for systematic and focused randomised controlled trials, with inclusion criteria as well as outcome assessment performed objectively. Video-recorded verification of laryngeal obstruction may be of value, not only as a diagnostic tool, but also as a therapeutic measure. Simply observing their own malfunctioning larynx has been reported to be of help in a majority of patients with mild or moderate disease [55]. Furthermore, simply identifying the problem may prevent inappropriate escalation of asthma therapy [74].

\section{Medical treatment}

Removal of irritants

GOR may be a trigger for ILO, and thus antireflux therapy has been reported to be efficacious by some [75], but not all $[27,52]$ authors.

\section{Speech therapy/physiotherapy/psychology support}

Speech therapy ILO treatments have applied various techniques with different reported outcomes [1, 39, 43, 52, 76-80]. Examples are nasal breathing, panting and diaphragmatic breathing [1, 76, 81]. Any method, such as speech therapy, that focuses attention away from the larynx (e.g. nasal breathing, diaphragmatic breathing) may have an effect through distracting the attention away from breathing problems and refocusing attention to a specific task (e.g. exercise).

Psychological mechanisms may have wide implications for various presentations of ILO. Several authors have reported successful treatment of ILO by psychotherapy $[1,82])$. There is limited experience with hypnotherapy $[83,84]$ and biofeedback $[39,85,86]$. Psychotherapy or psychological counselling is often accompanied by speech therapy [1, 79, 87], and described with biofeedback [85].

Generally, a number of treatment strategies are aimed at avoidance of exposure to presumed inducers or represent methods for improved coping, including psychotherapy or psychological counselling, behavioural modifications and distraction techniques, including breathing techniques focusing attention away from the larynx. There is certainly a need to standardise these techniques.

\section{Medicinal therapies}

Inhaled anticholinergics (ipratropium) have been reported to reduce symptoms in exercise-induced VCD [88]. Properly conducted randomised controlled trials are needed.

Successful use of low-dose tricyclic antidepressants (amitriptyline) for night sedation was described in a group of 62 patients (age 18-90 years) in conjunction with a broad therapeutic approach, including speech and language therapy and in many cases the additional use of selective serotonin reuptake inhibitors. The authors called for randomised controlled trials before conclusions can be drawn [89].

\section{Inspiratory muscle training}

Case reports describe the application of inspiratory muscle strength training. It is speculated that laryngeal muscle strength is increased, possibly increasing the size of the inspiratory laryngeal aperture, as well as increasing respiratory muscle strength $[90,91]$. However, an increase in laryngeal muscle strength has not been demonstrated. A potential concern is that enhancing the ability of the diaphragm and inspiratory accessory muscles to generate increased flow might be counterproductive if the larynx remains the critical restriction of ventilatory capacity. SANDNES et al. [92] showed that inspiratory muscle training did in fact produce laryngeal abduction in a healthy population. 
Heliox

Heliox has been shown to relieve symptoms during an ILO episode and symptoms may remain resolved following gas withdrawal [1], possibly by reducing the work of breathing. A placebo effect cannot be excluded, as with so many interventions. Moreover, this treatment modality is impractical for most episodes of ILO.

\section{Botulinum toxin injection}

Experience in the treatment of ILO with botulinum toxin injections in the vocal folds is limited [86, 93-95]. In most cases, the treatment has led to resolution of the immediate symptoms, yet in some only with a transient effect, and in one case no effect at all [95]. From this paucity of evidence, it is not possible to determine the safety and efficacy of botulinum toxin injections. In addition, the indications for its use remain unclear and further studies are needed to determine the role of botulinum toxin injections as treatment for ILO.

\section{Surgical treatment}

Supraglottoplasty

Based on the finding that supraglottic ILO during exercise shows similarities to laryngomalacia in infants [57], several ENT surgeons have performed supraglottic surgery in patients with severe EILO and clinically significant breathing problems [55, 57, 96-100]. Collectively, $<100$ patients have been described, and all studies report benefit. The aim of the surgery has been to lower the height of the aryepiglottic fold in order to widen the laryngeal inlet and reduce laryngeal obstruction, thereby increasing exercise ventilatory capacity. These procedures resemble those performed in children with laryngomalacia, and have so far been performed in patients with supraglottic EILO without reports of serious complications [55, 98, 99]. By nature, supraglottoplasty is a treatment for supraglottic EILO (i.e. not for glottic forms of EILO); therefore underpinning the importance of CLE testing to establish the structural anatomical cause underlying each case of EILO [55]. To date, no randomised controlled trials of surgical treatment have been performed and indeed neither the optimal surgical technique nor the long-term outcome has been established. Thus, the current standard of care should restrict surgery to refractory cases that have failed non-invasive treatment and the principles outlined under the concept of "shared decision making" should be carefully applied $[101,102]$.

\section{Recommendations for future research}

Our comprehensive review of the literature addressing ILO has highlighted a paucity of reliable data in this important field of respiratory medicine. This limits our ability to provide robust clinical statements and/or recommendations and at the current time, this applies to all aspects of ILO, including understanding of the pathophysiology and aetiology, diagnostic approach and optimal treatment and surveillance practice. In addition, there is no clear-cut definition or reliable and reproducible diagnostic scoring or assessment system for this condition, opening a real risk of diagnostic imprecision. Our understanding of ILO thus remains at an early stage, which is concerning given its high prevalence, i.e. EILO reported in up to one in 10 young people. This task force has assessed and summarised the best available data to produce statements outlining current clinical practice, and to serve to identify key areas for future research.

It is highly unlikely that ILO is a single disease entity. Our current understanding of ILO rests on typical images of a decreasing size of the laryngeal inlet obtained during typical symptoms. These images can tell us the extent of laryngeal narrowing relative to some baseline measurement obtained in patients. The images do not enable measurement of the absolute laryngeal size, information that is needed to clarify what is an abnormal versus a normal or even an optimal laryngeal size for any given body habitus, functional level or sex. The images also do not tell us what should be considered a pathological narrowing when symptoms do occur, either at rest as in irritant ILO, or with increasing minute ventilation as in exercise ILO. Thus, techniques that enable objective assessment of the size of the laryngeal lumen with simultaneous full visual representation would be highly valuable, and appear to be an important first priority to move the field forward. Such techniques should be accurate and reproducible, applicable in any provocation setting, including exercise, and should not alter laryngeal dynamics, the very object of the assessment. Knowledge of the pressure drops and gradients over the laryngeal entrance area, i.e. from the epipharyngeal via the supraglottic, midglottic, glottic and subglottic spaces would contribute to the understanding of what structures are causally involved in eliciting and perpetuating symptoms, particularly in exercise ILO. Given the discomfort of laryngoscopy, most studies of laryngeal function have been performed in patients reporting symptoms, often with an insufficient number of healthy controls. Thus, we need more information on the range of normality, applying accurate and reproducible tests in heterogeneous groups that are large enough to serve as normative populations. Such datasets can aid the development of computer-based simulation programmes that will increase our level of understanding and 
enable better predictions of effects from treatments. Given the discomfort and the resource-intensive nature of laryngoscopy, the development of less invasive or surrogate diagnostic methods is an obvious goal. However, at present, techniques that omit laryngoscopy seem unlikely to enable a distinction between glottic and supraglottic ILO, which is essential for further treatment and handling, particularly if laser supraglottoplasty is considered. The heterogeneity of findings reported from recent studies indicate that better phenotypic classification can facilitate individually tailored treatment, and indeed increase the success rates for treatment modalities other than surgery. These are all obvious issues to target in future research.

The role of psychological factors is controversial, probably reflecting the lack of an evidence base, including truly objective diagnostic tests. Thus, the role played by factors such as past and present stress, psychological factors, personality traits and even mental disorders need to be addressed in future carefully designed studies.

Future treatment studies must acknowledge the complex nature of laryngeal form and function in health and disease, and must categorise the patients carefully. Studies should at least discriminate between ILO occurring at rest and during exercise, and whether glottic or supraglottic structures are primarily involved. In particular, the place of surgery in these patients needs to be addressed in randomised controlled trials.

\section{Concluding remarks}

The aim of this task force document was to provide a concise state-of-the-art overview of the current research evidence evaluating ILO. This appraisal process and summary document has highlighted the fact that ILO is an important and prevalent entity and has considerable clinical impact for those affected with the condition. However, it is clear from our review that despite considerable progress and an evolving and strengthening evidence base within this field, our understanding of many aspects of ILO remains at a relatively embryonic stage. Specifically, our understanding of the aetiology and pathophysiology remain

\section{BOX 1 Summary of recommendations for future research}

Develop a valid, reproducible and accurate diagnostic test for ILO that does not alter laryngeal dynamics and is widely applicable as a gold standard

Uncover aetiology and pathophysiological mechanisms

Determine the range of normal variation

Examine heredity and genetic factors and predispositions

Develop validated screening tools and more easily available diagnostic surrogate tests

Develop standardised speech and language therapy and respiratory physiotherapy interventions

Develop targeted pharmaceutical and surgical interventions based on pathophysiological components

Test interventions in adequately powered randomised controlled trials

Establish prevalence in unselected populations outside of Scandinavia

Update nomenclature as the field progresses

Form guidelines for diagnosis and treatment

\section{BOX 2 Key facts}

ILO most commonly presents as exertional dyspnoea, but can present with ambiguous symptoms and signs, particularly when coexisting with other conditions

Symptoms are most often limited to the inspiratory phase; rarely to the expiratory phase

At present, visualisation of the larynx during ongoing symptoms is the only objective way of making a complete anatomical diagnosis

Spirometry and other surrogate tests have poor sensitivity and specificity, but might provide useful clinical clues

Clinical signs of ILO include:

Self-limiting intermittent dyspnoea triggered by specific exposures or (more rarely) occurring at random Wheezing or stridor (can be absent or difficult to distinguish from normal heavy breathing during intense exercise)

Likely triggers include (but are not limited to):

Exercise

Chemicals and odours

Anxiety and psychological stress

Management options include speech and language therapy, respiratory physiotherapy, inspiratory muscle training, various medicinal remedies and supraglottoplasty, and additionally, the optimisation

of treatment of any relevant comorbidity 
poor and despite considerable technological advances, robust, validated, diagnostic and treatment algorithms are yet to be established. Remarkably, there are currently no randomised controlled studies evaluating therapeutic interventions in ILO. Overall, our appraisal process has acted to highlight a number of important deficiencies in current knowledge in the field, and to present a number of key research priorities with the main aim of helping to improve our understanding to afford improved care to individuals suffering with ILO.

\section{Acknowledgements}

Following the publication of the initial inducible laryngeal obstruction nomenclature document [4] Kent Christopher and Michael Morris (American College of Chest Physicians) and Pernille Christensen (European Respiratory Society) voluntarily withdrew from the task force. We would like to acknowledge their significant contribution in progressing the task force to its current position and in assisting in the early drafting of this document.

\section{References}

1 Christopher KL, Wood RP, Eckert RC, et al. Vocal-cord dysfunction presenting as asthma. N Engl J Med 1983; 308: $1566-1570$.

2 Røksund OD, Maat RC, Heimdal J-H, et al. Exercise induced dyspnea in the young. Larynx as the bottleneck of the airways. Respir Med 2009; 103: 1911-1918.

3 Johansson $\mathrm{H}$, Norlander $\mathrm{K}$, Berglund L, et al. Prevalence of exercise-induced bronchoconstriction and exercise-induced laryngeal obstruction in a general adolescent population. Thorax 2015; 70: 57-63.

4 Christensen PM, Heimdal J-H, Christopher KL, et al. ERS/ELS/ACCP 2013 international consensus conference nomenclature on inducible laryngeal obstructions. Eur Respir Rev 2015; 24: 445-450.

5 Newman KB, Mason UG 3rd, Schmaling KB. Clinical features of vocal cord dysfunction. Am J Respir Crit Care Med 1995; 152: 1382-1386.

6 Nielsen EW, Hull JH, Backer V. High prevalence of exercise-induced laryngeal obstruction in athletes. Med Sci Sports Exerc 2013; 45: 2030-2035.

7 Walsted ES, Hull JH, Sverrild A, et al. Bronchial provocation testing does not detect exercise-induced laryngeal obstruction. J Asthma 2017; 54: 77-83.

8 Fowler SJ, Thurston A, Chesworth B, et al. The VCDQ - a questionnaire for symptom monitoring in vocal cord dysfunction. Clin Exp Allergy 2015; 45: 1406-1411.

9 Gartner-Schmidt JL, Shembel AC, Zullo TG, et al. Development and validation of the dyspnea index (DI): a severity index for upper airway-related dyspnea. $J$ Voice 2014; 28: 775-782.

10 Traister RS, Fajt ML, Landsittel D, et al. A novel scoring system to distinguish vocal cord dysfunction from asthma. J Allergy Clin Immunol Pract 2014; 2: 65-69.

11 Heimdal J-H, Roksund OD, Halvorsen T, et al. Continuous laryngoscopy exercise test: a method for visualizing laryngeal dysfunction during exercise. Laryngoscope 2006; 116: 52-57.

12 Maat RC, Røksund OD, Halvorsen T, et al. Audiovisual assessment of exercise-induced laryngeal obstruction: reliability and validity of observations. Eur Arch Otorhinolaryngol 2009; 266: 1929-1936.

13 Olin JT, Clary MS, Fan EM, et al. Continuous laryngoscopy quantitates laryngeal behaviour in exercise and recovery. Eur Respir J 2016; 48: 1192-1200.

14 Higenbottam T. Narrowing of glottis opening in humans associated with experimentally induced bronchoconstriction. J Appl Physiol Respir Environ Exerc Physiol 1980; 49: 403-407.

15 Jain S, Bandi V, Officer T, et al. Role of vocal cord function and dysfunction in patients presenting with symptoms of acute asthma exacerbation. J Asthma 2006; 43: 207-212.

16 Collett PW, Brancatisano T, Engel LA. Spasmodic croup in the adult. Am Rev Respir Dis 1983; 127: 500-504.

17 Christensen P, Thomsen SF, Rasmussen N, et al. Exercise-induced laryngeal obstructions objectively assessed using EILOMEA. Eur Arch Otorhinolaryngol 2010; 267: 401-407.

18 Patel NJ, Jorgensen C, Kuhn J, et al. Concurrent laryngeal abnormalities in patients with paradoxical vocal fold dysfunction. Otolaryngol Head Neck Surg 2004; 130: 686-689.

19 Tervonen H, Niskanen MM, Sovijärvi AR, et al. Fiberoptic videolaryngoscopy during bicycle ergometry: a diagnostic tool for exercise-induced vocal cord dysfunction. Laryngoscope 2009; 119: 1776-1780.

20 Panchasara B, Nelson C, Niven R, et al. Lesson of the month: rowing-induced laryngeal obstruction: a novel cause of exertional dyspnoea: characterised by direct laryngoscopy. Thorax 2015; 70: 95-97.

21 Christensen PM, Thomsen SF, Rasmussen N, et al. Exercise-induced laryngeal obstructions: prevalence and symptoms in the general public. Eur Arch Otorhinolaryngol 2011; 268: 1313-1319.

22 Garcia de la Rubia S, Pajarón-Fernandez MJ, Sanchez-Solís M, et al. Exercise-induced asthma in children: a comparative study of free and treadmill running. Ann Allergy Asthma Immunol 1998; 80: 232-236.

23 Perkner JJ, Fennelly KP, Balkissoon R, et al. Irritant-associated vocal cord dysfunction. J Occup Environ Med 1998; 40: 136-143.

24 Marcinow AM, Thompson J, Forrest LA, et al. Irritant-induced paradoxical vocal fold motion disorder: diagnosis and management. Otolaryngol Head Neck Surg 2015; 153: 996-1000.

25 Huggins JT, Kaplan A, Martin-Harris B, et al. Eucalyptus as a specific irritant causing vocal cord dysfunction. Ann Allergy Asthma Immunol 2004; 93: 299-303.

26 Sakthivel P, Ranipatel S, Singh I, et al. Paradoxical vocal cord movement during sleep - a unique case with review of literature. Int J Pediatr Otorhinolaryngol 2015; 79: 1946-1948.

27 Woolnough K, Blakey J, Pargeter N, et al. Acid suppression does not reduce symptoms from vocal cord dysfunction, where gastro-laryngeal reflux is a known trigger. Respirology 2013; 18: 553-554.

28 Cummings KJ, Fink JN, Vasudev M, et al. Vocal cord dysfunction related to water-damaged buildings. J Allergy Clin Immunol Pract 2013; 1: 46-50.

29 Tonini S, Dellabianca A, Costa C, et al. Irritant vocal cord dysfunction and occupational bronchial asthma: differential diagnosis in a health care worker. Int J Occup Med Environ Health 2009; 22: 401-406. 
de la Hoz RE, Shohet MR, Bienenfeld LA, et al. Vocal cord dysfunction in former World Trade Center (WTC) rescue and recovery workers and volunteers. Am I Ind Med 2008; 51: 161-165.

Muñoz X, Roger A, De la Rosa D, et al. Occupational vocal cord dysfunction due to exposure to wood dust and xerographic toner. Scand J Work Environ Health 2007; 33: 153-158.

Herin F, Poussel M, Renaudin J-M, et al. A 38-year-old hairdresser with irritant-associated vocal cord dysfunction. Int J Tuberc Lung Dis 2012; 16: 138-139.

Galdi E, Perfetti L, Pagella F, et al. Irritant vocal cord dysfunction at first misdiagnosed as reactive airway dysfunction syndrome. Scand J Work Environ Health 2005; 31: 224-226.

Perkins MPJ, Morris LMJ. Vocal cord dysfunction induced by methacholine challenge testing. Chest 2002; 122: 1988-1993.

Bucca C, Rolla G, Scappaticci E, et al. Histamine hyperresponsiveness of the extrathoracic airway in patients with asthmatic symptoms. Allergy 1991; 46: 147-153.

Bucca C, Rolla G, Brussino L, et al. Are asthma-like symptoms due to bronchial or extrathoracic airway dysfunction? Lancet 1995; 346: 791-795.

Christopher KL, Morris MJ. Vocal cord dysfunction, paradoxic vocal fold motion, or laryngomalacia? Our understanding requires an interdisciplinary approach. Otolaryngol Clin North Am 2010; 43: 43-66.

Brugman SM, Simons SM. Vocal cord dysfunction: don't mistake it for asthma. Phys Sportsmed 1998; 26: 63-85.

McFadden ER, Zawadski DK. Vocal cord dysfunction masquerading as exercise-induced asthma. A physiologic cause for "choking" during athletic activities. Am J Respir Crit Care Med 1996; 153: 942-947.

Rundell KW, Spiering BA. Inspiratory stridor in elite athletes. Chest 2003; 123: 468-474.

Christensen PM, Rasmussen N. Eucapnic voluntary hyperventilation in diagnosing exercise-induced laryngeal obstructions. Eur Arch Otorhinolaryngol 2013; 270: 3107-3113.

Lakin RC, Metzger WJ, Haughey BH. Upper airway obstruction presenting as exercise-induced asthma. Chest 1984; 86: 499-501.

Morris MJ, Deal LE, Bean DR, et al. Vocal cord dysfunction in patients with exertional dyspnea. Chest 1999; 116: $1676-1682$.

Corren J, Newman KB. Vocal cord dysfunction mimicking bronchial asthma. Postgrad Med 1992; 92: 153-156. Christensen PM, Maltbæk N, Jørgensen IM, et al. Can flow-volume loops be used to diagnose exercise induced laryngeal obstructions? A comparison study examining the accuracy and inter-rater agreement of flow volume loops as a diagnostic tool. Prim Care Respir J 2013; 22: 306-311.

Hira HS, Singh A. Significance of upper airway influence among patients of vocal cord dysfunction for its diagnosis: role of impulse oscillometry. Lung India 2009; 26: 5-8.

Komarow HD, Young M, Nelson C, et al. Vocal cord dysfunction as demonstrated by impulse oscillometry. Allergy Clin Immunol Pract 2013; 1: 387-393.

Gallena SJK, Solomon NP, Johnson AT, et al. The effect of exercise on respiratory resistance in athletes with and without paradoxical vocal fold motion disorder. Am J Speech Lang Pathol 2015; 24: 470-479.

Bikov A, Pride NB, Goldman MD, et al. Glottal aperture and buccal airflow leaks critically affect forced oscillometry measurements. Chest 2015; 148: 731-738. Care Med 2011; 184: 50-56.

Leo RJ, Konakanchi R. Psychogenic respiratory distress: a case of paradoxical vocal cord dysfunction and literature review. Prim Care Companion J Clin Psychiatry 1999; 1: 39-46.

Maturo S, Hill C, Bunting G, et al. Pediatric paradoxical vocal-fold motion: presentation and natural history. Pediatrics 2011; 128: e1443-e1449.

Kenn K, Schmitz M. "Vocal Cord Dysfunction" (VCD), eine wichtige Differentialdiagnose zum schweren und inplausiblen Asthma bronchiale. [Vocal cord dysfunction, an important differential diagnosis of severe and implausible bronchial asthma]. Pneumologie 1997; 51: 14-18.

Morris MJ, Christopher KL. Diagnostic criteria for the classification of vocal cord dysfunction. Chest 2010; 138: 1213-1223.

Maat RC, Hilland M, Røksund OD, et al. Exercise-induced laryngeal obstruction: natural history and effect of surgical treatment. Eur Arch Otorhinolaryngol 2011; 268: 1485-1492.

Strohl KP, Butler JP, Malhotra A. Mechanical properties of the upper airway. Compr Physiol 2012; 2: 1853-1872.

Smith RJH, Bauman NM, Bent JP, et al. Exercise-induced laryngomalacia. Ann Otol Rhinol Laryngol 1995; 104: 537-541.

Hilland M, Røksund OD, Sandvik L, et al. Congenital laryngomalacia is related to exercise-induced laryngeal obstruction in adolescence. Arch Dis Child 2016; 101: 443-448.

Petcu LG, Sasaki CT. Laryngeal anatomy and physiology. Clin Chest Med 1991; 12: 415-423.

Hast MH. The developmental anatomy of the larynx. Otolaryngol Clin North Am 1970; 3: 413-438.

Wysocki J, Kielska E, Orszulak P, et al. Measurements of pre- and postpubertal human larynx: a cadaver study. Surg Radiol Anat 2008; 30: 191-199.

Castelli WA, Ramirez PC, Nasjleti CE. Linear growth study of the pharyngeal cavity. J Dent Res 1973; 52: $1245-1248$.

Thompson DM. Abnormal sensorimotor integrative function of the larynx in congenital laryngomalacia: a new theory of etiology. Laryngoscope 2007; 117: 1-33.

Yelken K, Yilmaz A, Guven M, et al. Paradoxical vocal fold motion dysfunction in asthma patients. Respirology 2009; 14: 729-733.

Cukier-Blaj S, Bewley A, Aviv JE, et al. Paradoxical vocal fold motion: a sensory-motor laryngeal disorder. Laryngoscope 2008; 118: 367-370.

Patterson R, Schatz M, Horton M. Munchausen's stridor: non-organic laryngeal obstruction. Clin Exp Allergy 1974; 4: 307-310.

Guglani L, Atkinson S, Hosanagar A, et al. A systematic review of psychological interventions for adult and pediatric patients with vocal cord dysfunction. Front Pediatr 2014; 2: 82.

unsein OF, Husein TN, Gardner R, et al. Formal psychological testing in patients with paradoxical vocal fold dysfunction. Laryngoscope 2008; 118: 740-747. 
Higenbottam T, Payne J. Glottis narrowing in lung disease. Am Rev Respir Dis 1982; 125: 746-750. Bush A, Fleming L. Diagnosis and management of asthma in children. BMJ 2015; 350: h996.

Phua SY, McGarvey LPA, Ngu MC, et al. Patients with gastro-oesophageal reflux disease and cough have impaired laryngopharyngeal mechanosensitivity. Thorax 2005; 60: 488-491.

Phua S-Y, McGarvey L, Ngu M, et al. The differential effect of gastroesophageal reflux disease on mechanostimulation and chemostimulation of the laryngopharynx. Chest 2010; 138: 1180-1185.

Peters EJ, Hatley TK, Crater SE, et al. Sinus computed tomography scan and markers of inflammation in vocal cord dysfunction and asthma. Ann Allergy Asthma Immunol 2003; 90: 316-322.

Bush A, Saglani S. Management of severe asthma in children. Lancet 2010; 376: 814-825.

Boris M, Goldblatt A, Krigsman A. Laryngeal dysfunction: a common cause of respiratory distress, often misdiagnosed as asthma and responsive to antireflux therapy. Allergy Asthma Proc 2002; 23: 133-139.

Rameau A, Foltz RS, Wagner K, et al. Multidisciplinary approach to vocal cord dysfunction diagnosis and treatment in one session: a single institutional outcome study. Int J Pediatr Otorhinolaryngol 2012; 76: 31-35.

Kayani S, Shannon DC. Vocal cord dysfunction associated with exercise in adolescent girls. Chest 1998; 113: 540-542.

Landwehr LP, Wood RP, Blager FB, et al. Vocal cord dysfunction mimicking exercise-induced bronchospasm in adolescents. Pediatrics 1996; 98: 971-974.

Andrianopoulos MV, Gallivan GJ, Gallivan KH. PVCM, PVCD, EPL, and irritable larynx syndrome: what are we talking about and how do we treat it? J Voice 2000; 14: 607-618.

Sullivan MD, Heywood BM, Beukelman DR. A treatment for vocal cord dysfunction in female athletes: an outcome study. Laryngoscope 2001; 111: 1751-1755.

Newsham KR, Klaben BK, Miller VJ, et al. Paradoxical vocal-cord dysfunction: management in athletes. $J$ Ath Train 2002; 37: 325-328.

Elshami AA, Tino G. Coexistent asthma and functional upper airway obstruction. Case reports and review of the literature. Chest 1996; 110: 1358-1361.

Anbar RD, Hehir DA. Hypnosis as a diagnostic modality for vocal cord dysfunction. Pediatrics 2000; 106 : e81.

Anbar RD. Hypnosis in pediatrics: applications at a pediatric pulmonary center. BMC Pediatr 2002; 2: 11 .

Selner JC, Staudenmayer H, Koepke JW, et al. Vocal cord dysfunction: the importance of psychologic factors and provocation challenge testing. J Allergy Clin Immunol 1987; 79: 726-733.

Altman KW, Mirza N, Ruiz C, et al. Paradoxical vocal fold motion: presentation and treatment options. J Voice 2000; 14: 99-103.

Gallivan GJ, Hoffman L, Gallivan KH. Episodic paroxysmal laryngospasm: voice and pulmonary function assessment and management. J Voice 1996; 10: 93-105.

Doshi DR, Weinberger MM. Long-term outcome of vocal cord dysfunction. Ann Allergy Asthma Immunol 2006; 96: 794-799.

Varney V, Parnell H, Evans J, et al. The successful treatment of vocal cord dysfunction with low-dose amitriptyline - including literature review. J Asthma Allergy 2009; 2: 105-110.

Archer GJ, Hoyle JL, McCluskey A, et al. Inspiratory vocal cord dysfunction, a new approach in treatment. Eur Respir J 2000; 15: 617-618.

Mathers-Schmidt BA, Brilla LR. Inspiratory muscle training in exercise-induced paradoxical vocal fold motion. Voice 2005; 19: 635-644.

Sandnes A, Andersen T, Hilland M, et al. Laryngeal movements during inspiratory muscle training in healthy subjects. J Voice 2013; 27: 448-453.

Montojo J, González R, Hernández E, et al. Office-based laryngeal injection of botulinum toxin for paradoxical vocal fold motion in a child. Int J Pediatr Otorhinolaryngol 2015; 79: 1161-1163.

Cheng YS, Bhutta MF, Ramsden JD, et al. Periodic botulinum toxin injections for paradoxical vocal fold motion in a child with cerebral palsy: a case study. Int J Pediatr Otorhinolaryngol 2014; 78: 570-571.

Goldstein R, Bright J, Jones SM, et al. Severe vocal cord dysfunction resistant to all current therapeutic interventions. Respir Med 2007; 101: 857-858.

Bent JP, Miller DA, Kim JW, et al. Pediatric exercise-induced laryngomalacia. Ann Otol Rhinol Laryngol 1996; 105: 169-175.

Maat RC, Roksund OD, Olofsson J, et al. Surgical treatment of exercise-induced laryngeal dysfunction. Eur Arch Otorhinolaryngol 2007; 264: 401-407.

Sidell DR, Balakrishnan K, Hart CK, et al. Pediatric exercise stress laryngoscopy following laryngotracheoplasty: a comparative review. Otolaryngol Head Neck Surg 2014; 150: 1056-1061.

Norlander K, Johansson H, Jansson C, et al. Surgical treatment is effective in severe cases of exercise-induced laryngeal obstruction: a follow-up study. Acta Otolaryngol 2015; 135: 1152-1159.

Mehlum CS, Walsted ES, Godballe C, et al. Supraglottoplasty as treatment of exercise induced laryngeal obstruction (EILO). Eur Arch Otorhinolaryngol 2016; 273: 945-951.

1 Elwyn G, Edwards A, Eccles M, et al. Decision analysis in patient care. Lancet 2001; 358: 571-574.

Elwyn G, Frosch D, Thomson R, et al. Shared decision making: a model for clinical practice. J Gen Intern Med 2012; 27: 1361-1367.

Tilles SA, Ayars AG, Picciano JF, et al. Exercise-induced vocal cord dysfunction and exercise-induced laryngomalacia in children and adolescents: the same clinical syndrome? Ann Allergy Asthma Immunol 2013; 111: 342-346

Marcinow AM, Thompson J, Chiang T, et al. Paradoxical vocal fold motion disorder in the elite athlete: experience at a large division I university. Laryngoscope 2014; 124: 1425-1430.

2012; 40: 28-33. 